\title{
Advancements in diagnostic solutions for complex viruses: an interview with Ralph Schimmer
}

\author{
Alice Greenway*,1 \& Ralph Schimmer ${ }^{2}$ \\ ${ }^{1}$ Future Medicine, London, UK \\ ${ }^{2}$ Roche Diagnostics International Ltd, Risch-Rotkreuz, Switzerland \\ *Author for correspondence: alicee.greenway@googlemail.com
}

Ralph Schimmer, MD, MBA speaks to Alice Greenway, Commissioning Editor of Future Virology. Ralph has been Chief Medical Officer and Head Global Medical \& Scientific Affairs for Centralized and Point of Care Solutions within the Roche Diagnostics division since May 2014. Between 2012 and 2016, Ralph was the Roche coordinator of the Innovative Medicines Initiative's (IMI) project Eu2P, a public-private partnership with a consortium of seven European universities, 15 pharmaceutical companies and the European and French Medicines Agencies. The Commissioning Editor of Future Virology, Alice Greenway, talks to Schimmer about the role that Roche Diagnostics plays in the development of tailored diagnostic solutions for complex viruses as well as the launch of the new Elecsys ${ }^{\circledR}$ Zika IgG assay.

First draft submitted: 24 April 2018; Accepted for publication: 27 April 2018; Published online:

7 June 2018

Keywords: complex viruses $\bullet$ diagnostics $\bullet$ immunoassay $\bullet$ infectious diseases $\bullet$ zika

\section{Q1: Please could you introduce yourself \& tell us a little about your background?}

A: My name is Ralph Schimmer and I am Chief Medical Officer and Head of Global Medical and Scientific Affairs for Centralized and Point of Care Solutions (CPS) within Roche Diagnostics.

I am responsible for leading the CPS Clinical Development and Medical Affairs organization that has approximately 250 employees worldwide across several sites. Our focus is on driving innovation in medical and technological diagnostic solutions that aim to support healthcare decisions to improve medical outcomes, and ultimately, people's lives.

\section{Q2: In your opinion, what are the key hurdles to be overcome in the field of complex} infectious disease diagnostics, \& what role does Roche Diagnostics International Ltd play in overcoming these hurdles?

$A$ : Some of the biggest hurdles to overcome within this field include keeping pace with both existing and emerging infectious diseases that have proliferated in our fast-paced global environment. Curbing the emergence of new infectious diseases is further complicated by changes in demographics, environmental and social factors.

The rise in preventable infectious diseases, particularly in vulnerable, low-income countries is becoming increasingly challenging. But also developed countries are more affected by emerging infections due to widespread travel activities and global warming. Despite global efforts and successes, such as the $2000 \mathrm{WHO}$ (Millennium Development Goals), developing and low-income countries are still burdened by the spread of preventable diseases. Also, infectious diseases believed to have been eliminated are now proving to be resistant to treatment.

Roche is always looking for opportunities to apply scientific and technological expertise to overcome the spread of preventable diseases that present significant global public health challenges. We use the experience that we have in developing breakthrough diagnostic solutions for infectious diseases, such as HIV/AIDs, viral Hepatitis and Cytomegalovirus infections, to progress further the development of highly sophisticated and accurate diagnostic tests. The launch of the Elecsys ${ }^{\circledR}$ Zika IgG assay is the latest example of Roche's ongoing commitment to tackle infectious diseases. 


\section{Q3: What would you say has been the biggest advancement in diagnostic solutions for complex infectious diseases in the last 5 years?}

$A$ : Among the most prominent advancements and medical needs in the field of infectious diseases is Zika virus and the increasing understanding of this infection with its link to the brain. Thus, I would regard the ability to diagnose the infection and the disease state as an important advancement over the past few years.

Another area with high medical needs is certainly antibiotic resistance, which continues to spread globally. Roche is strongly engaged in the research and development of tests to detect specific bacterial and viral infections, as well as in the development of new antibiotics.

Looking specifically at diagnostic solutions in the area of complex infectious diseases, I would definitely mention two main impactful advancements. First, the introduction of mass spectrometry into the clinical microbiology laboratory which allows for more rapid and cost-efficient identification of pathogens. Second, the broadening of the availability of multiplexed assays for pathogen detection. Major ongoing impactful trends are represented by the increasing importance of understanding and characterizing the gut microbiome, evolving techniques for rapid antimicrobial susceptibility testing, and the introduction of full automation in the microbiology laboratory.

\section{Q4: Communication \& collaboration are really important in helping the field progress faster. What does Roche do to encourage collaboration?}

$A$ : Roche has a strong legacy in healthcare innovation, and was one of the first companies to bring targeted treatments to patients. Today, Roche creates innovative medicines and diagnostic solutions that help millions of patients globally. With this heritage comes a responsibility to use our scientific capabilities and expertise to help address some of the largest global public health threats like the Zika virus.

Roche's rapid engagement allowed us to fast-track the development of the Elecsys Zika IgG prototype assay in under a year. Development of the Elecsys Zika IgM was also started, with antigen generation and optimization. The first milestone in the development process was passed successfully in November 2017.

We also recognize the importance of collaboration to drive sustainable access for diagnostics in countries with the greatest disease burden and the least resources. One example of this is Amplicare, a programme that has been in place since 2002, designed to increase access to HIV viral load tests at substantially reduced prices in sub-Saharan Africa and countries where the disease burden is highest. In 2014, we collaborated with other organizations to launch the Global Access Programme. The Global Access Programme supports the 90-90-90 UNAIDS goal, expanding access to sustainable diagnostic testing for countries hardest hit by HIV and works hand in hand with Amplicare. As part of this we have partnered with UNAIDS (the joint United Nations programme on HIV/AIDS), Clinton Health Access Initiative, President's Emergency Plan for AIDS Relief, Global Fund to Fight AIDS, TB and Malaria.

\section{Q5: In regards to both diagnostics \& treatment how has Roche responded to the Zika global epidemic?}

A: Following the 2016 WHO declaration of Zika virus being a public health emergency, Roche initiated several projects including:

- The development of the cobas ${ }^{\circledR}$ Zika test, for blood donor screening purposes, by Roche Molecular Diagnostics; - The fast-tracked development of the Elecsys ${ }^{\circledR}$ Zika IgG serology test, for clinical diagnostic purposes, by CPS;

- Development of the Elecsys Zika IgM serology test was also initiated.

The cobas ${ }^{\circledR}$ Zika test was granted IVD status by the US Food and Drug Administration (FDA) on 5 October 2017, for the use with the cobas $6800 / 8800$ systems for the screening of blood and plasma donations for patients in the USA to reduce the risk of contaminated blood transfusions.

\section{Q6: Could you introduce the Elecsys ${ }^{\circledR}$ Zika IgG assay \& tell us a little more about how it works?}

A: The Elecsys Zika IgG assay is an immunoassay for the in vitro qualitative detection of IgG antibodies to detect Zika virus in human serum and plasma. The test takes $18 \mathrm{~min}$ and is intended as an aid in the diagnosis of infection with Zika virus.

Laboratory evidence of Zika infection is obtained by testing samples for viral nucleic acid or virus-specific IgM and IgG antibodies. IgM levels are variable and are detectable starting near day 2 post onset of symptoms. IgG 
antibodies develop within days after appearance of $\operatorname{IgM}$ ( $5-8$ days after the symptoms onset) and can be detected for at least months to years [1,2]. Cases have been described with persistence of IgM antibodies for a longer period which complicates differentiation of recent and prior viral infection [3].

Serology-based diagnosis of Zika virus infection can pose a challenge due to the potential cross-reactivity of antibodies against related flaviviruses that are derived from natural infection or vaccination [4]. Due to the similarity of Zika virus to other viruses, such as Dengue virus, the Elecsys ${ }^{\circledR}$ Zika IgG assay has been developed to limit cross-reaction and reduce the occurrence of false-positive results.

\section{Test principle}

- Sandwich principle. Total duration of assay: $18 \mathrm{~min}$

- First incubation: $20 \mu \mathrm{l}$ of sample, biotinylated Zika-specific recombinant antigens and Zika-specific recombinant antigens labeled with a ruthenium complexa react to form a sandwich complex;

- Second incubation: After addition of streptavidin-coated microparticles, the complex becomes bound to the solid phase via interaction of biotin and streptavidin;

- The reaction mixture is aspirated into the measuring cell where the microparticles are magnetically captured onto the surface of the electrode. Unbound substances are then removed with ProCell/ProCell M. Application of a voltage to the electrode then induces chemiluminescent emission which is measured by a photomultiplier.

Results are determined automatically by the software by comparing the electrochemiluminescence signal obtained from the reaction product of the sample with the signal of the cut-off value previously obtained by calibration.

\section{Q7: What are the tests currently available for the detection of Zika \& how does this assay address an unmet need in affected areas?}

A: Since the 2016 Zika virus epidemic, application and evaluation of sensitive and specific diagnostic assays, particularly those that can be used in frontline laboratories, has become a top public health priority [5].

Currently available tests range from Zika virus serologic assays, to PCR tests to the Zika MAC-ELISA and plaque-reduction neutralization tests.

For certain patients presenting with clinical signs and symptoms associated with Zika virus infection, a PCR test is used to detect the RNA of the Zika virus in serum, whole blood, cerebrospinal fluid, urine or amniotic fluid. The PCR test will only detect the virus early after exposure, so a patient who has been recently infected and cleared of the virus may show a negative test result [6,7].

Because Zika virus is from the same family as the Dengue and Yellow Fever viruses, which co-circulate in endemic areas, it is important that serology tests are specific to Zika virus to avoid a cross-reaction with these other viruses and to reduce the potential for false-positive results [7].

Serology assays are important because they can detect a recent infection even when RNA virus is no longer present to determine the infection status, in other words, acute, recent or past infection. In addition, serological assays such as IgG are used to perform seroprevalence studies and assess the level of immune status in a country.

The new serological Zika IgG immunoassay for CE Mark countries meets an important medical need because it can provide an accurate diagnosis of Zika virus infection. It also helps healthcare professionals to assess the infection status, even when the virus's RNA is no longer detectable.

The Elecsys ${ }^{\circledR}$ Zika IgG assay has been developed as a highly specific assay to limit cross-reaction with other viruses, such as Dengue virus, and to reduce the occurrence of false positive results.

\section{Q8: An affordable \& accurate test for Zika virus is critical for public health; could you tell us a little bit about how \& where the test will be deployed \& how much this will cost?}

A: The Elecsys ${ }^{\circledR}$ Zika IgG immunoassay is available in CE Mark for countries. Deployment and cost will vary from country to country.

\section{Q9: What impact could this assay have for patients in the future?}

A: Despite no longer being declared a public health emergency by the WHO, Zika virus is still acknowledged as a significant enduring public health challenge requiring intense action. While symptoms of Zika virus infection are often mild and require no specific treatment, in some cases, the outcomes can be devastating. Evidence has shown 
for example that Zika virus infection may be linked to birth defects in foetuses and newborns and neurological complications in adults $[8,9]$.

With this in mind, and since there are currently no available vaccines to prevent Zika virus, it's important to develop swift and tailored solutions to accurately detect Zika virus infection to prevent future health risks to patients.

\section{Q10: What are the next steps in Roche Diagnostics International Ltd research in the battle against Zika?}

A: At Roche, we focus on the development of diagnostic and therapeutic products that are differentiated and address high medical needs. In this context, an important step will be the expansion of the Roche arbovirus assay panel to address the most important assays in the area of tropical fevers, for example, Zika IgM, Dengue assays, Chikungunya assays and other related virus assays to enable a specific diagnosis and discrimination of these viruses to accurately, target and manage a patient's disease.

There is also a clear need for a diagnostic test that can predict future immunity - be it following previous natural infection or a potential Zika vaccine.

\section{Disclaimer}

The opinions expressed in this interview are those of the interviewee and do not necessarily reflect the views of Future Medicine Ltd.

\section{Financial \& competing interests disclosure}

R Schimmer is an employee of Roche Diagnostics International Ltd. The interviewee has no other relevant affiliations or financial involvement with any organization or entity with a financial interest in or financial conflict with the subject matter or materials discussed in the manuscript apart from those disclosed. No writing assistance was utilized in the production of this manuscript.

\section{References}

1 Jeong YE, Cha GW, Cho JE et al. Viral and serological kinetics in Zika virus-infected patients in South Korea. Virol. J. 14, 70 (2017).

2 Lustig Y, Zelena H, Venturi G et al. Sensitivity and kinetics of an NS1-based zika virus enzyme-linked immunosorbent assay in zika virus-infected travelers from israel, the Czech Republic, Italy, Belgium, Germany, and Chile. J. Clin. Microbiol. 55(6), 1894-1901 (2017).

3 Cleton N, Koopmans M, Reimerink J et al. Come fly with me: review of clinically important arboviruses for global travelers. J. Clin. Virol. 55(3), 191-203 (2012).

3 Lanciotti RS, Kosoy OL, Laven JJ et al. Genetic and serologic properties of Zika virus associated with an epidemic, Yap State, Micronesia, 2007. Emerg. Infect. Dis. 14(8), 1232-1239 (2008).

4 David Safronetz et al. Evaluation of 5 commercially available Zika virus immunoassays. Emerg. Infect. Dis. 23(9), 1577-1580 (2017).

5 Centers for Disease Control and Prevention. Zika virus: types of tests (2017). www.cdc.gov/zika/hc-providers/types-of-tests.html

6 Duffy MR, Chen TH, Hancock WT et al. Zika virus outbreak on Yap Island, federated states of Micronesia. N. Engl. J. Med. 360, 2536-254 (2009).

7 Rasmussen SA, Jamieson DJ, Honein MA et al. Zika virus and birth defects - reviewing the evidence for causality. N. Engl. J. Med. 374(20), 1981-1987 (2016).

8 World Health Organization, Pan American Health Organization. Epidemiological update: neurological syndrome, congenital anomalies, and Zika virus infection (2016).

www.paho.org/hq/index.php?option=com_docman\&task=doc_view\&Itemid=270\&gid=32879\&lang=en 